International Journal of Research in Nursing 1 (2): 39-56, 2010

ISSN 1949-0194

(C) 2010 Science Publications

\title{
Let's Talk about Sex: An Evolving Research Program in Perinatal Sexuality
}

\author{
Viola Polomeno \\ School of Nursing, Faculty of Health Sciences, University of Ottawa, \\ 451, Chemin Smyth Ottawa, Ontario, K2C 4E4, Canada
}

\begin{abstract}
This article presents the definition of a research program and how to develop one. The author offers her own experience as an example. Problem statement: There was a dearth of literature on how-to articles on 'how to' establish a research program. Approach: This article presents the author's evolving research program in perinatal sexuality which focuses on the couple's intimacy in the transition to parenthood. The theoretical and clinical background leading up to the development of the research program was presented as well as preliminary findings from the first group of studies. Results: The current research program with its various research studies were featured next. Lastly, the author shares the lessons that she had learned about establishing a research program. Conclusion: More articles are needed in which researchers present their own personal experiences of how they developed their research programs.

Key words: Programmatic research, perinatal nursing, transition to parenthood, perinatal sexuality, research program, education programs, perinatal health, self-perceptions, clinical background, theoretical knowledge
\end{abstract}

\section{INTRODUCTION}

No one talks about sex in nursing even less within the perinatal context. Yet there is so much to say about this "hot" topic! Perinatal sexuality, a newly emerging domain within perinatal care, focuses on the couple's intimacy in the transition to parenthood. This transition is fraught with multiple changes as much for the woman as for her partner. Yet, it is the sexual dimension within intimacy which is the most affected by the transition to parenthood (Polomeno, 2000a). Few nurses are trained in sex research and even less, conduct research in perinatal sexuality.

This is an article of "a work in progress", meaning, a research program that is evolving in perinatal sexuality. Hardly anyone writes about how their research program came into effect, the clinical background that lead to it, the discoveries along the way and the training that was required at different stages of the process. There is a paucity of literature on the development of programmatic research (Austin, 2001; Moore and Singleton, 2009) in relation to this context.

This article is divided into seven sections. The first part explains what a research program is and the second one presents the background to my training as a nurse. The third section describes how perinatal sexuality came about followed by the conceptualization underlying my clinical practice in the fourth section. The fifth section presents preliminary findings from the first group of research studies that I conducted with the Polomeno intervention framework. The sixth section features the current research studies that are part of my actual research program at the University of Ottawa. Lastly, reflections are presented on the lessons that I have learned regarding the establishment of a research program.

The first question: What is a research program? Since this is a how-to article, the first question to be answered involves the definition of a research program as well as the types of research programs that exist and how are they funded (Table 1 which presents an explanation about research programs). A research program includes a series of research studies that have a common focus around a particular theme or topic. The objectives of the research program are clearly delineated so that its outcomes can be evaluated and that they contribute to advancing knowledge in that domain. The findings from the first research study are used to plan for the second one and the findings from the second one are used for the planning of the third one. At the end, the findings from all of the research studies included within the research program may be applied to conceptualize a second research program.

The beginning: I offer my own situation as an example. My undergraduate degree was a non-nursing one: I have a Bachelor of Science with a major in anatomy. I was trained in nursing at the master's level at McGill University in Montréal, Canada. I specialized in perinatal nursing while I was in it. This is a special master's program for direct entry students. 
Intl. J. Rec. Nursing 1 (2): 39-56, 2010

Table 1: What is a research program?

Question: What is a research program?

A research program includes a series of research projects that have been conceptualized around a research theme or a research question. The first research project generally focuses on the first stage of the research theme. The results of this first research project are then used for planning and conducting the second research project. This process follows till the objectives of the research program have been realized. A second research program may be developed based on the first one.

A research program can be developed by one person, by a group of researchers, by a research unit, or by a director of a research chair at different levels (school/department, university, national, international). The research program can be only local or it can be as complex as multicentered and international.

The research designs, the samples, the data collection methods and the settings will vary according to the purposes of the research projects contained within the research program. Some studies will be qualitative while others will be quantitative. The greater trend is for multi-method research projects.

Sometimes a research program is initiated by a researcher or by a group of researchers who have interests or concerns in common. These types of research programs are internally motivated. Other types of research programs are externally motivated, meaning, that they are born due to funding opportunities or due to invitations by specific people such as stakeholders, government agencies, or foundations.

Funding for research programs may be internal or external. Internal funding is provided within the institution itself, whereas external funding occurs from outside the agency or the institution itself. The amounts for funding will vary based on the complexity of the research project. Funding from external resources is becoming more difficult to obtain so interdisciplinary research teams are being encouraged to be created and to apply for such funding. In Canada, health research is primarily funded by the Canadian Institutes of Health Research (http://www.cihrirsc.gc.ca/e/193.html). However, major foundations are also funding research such as the Heart and Stroke Foundation of Canada, the Canadian Diabetes Association and the Canadian Cancer Society. In the United States, the major agency for external research funding comes from the National Institutes of Health (www.nih.gov/)

Established in 1974, it is still the only program of its type in Canada. At the time of my training, this master's program prepared nurses to be researchers and clinicians at the same time, thus students had to conduct a research study and a clinical one. This is a theme that is present throughout my career: how my clinical practice stimulates my research and how the findings from my research are then applied back to my clinical practice.

While in the master's program, my research interest was on perinatal care, particularly the impact of cesarean birth on fathers, while my clinical one involved perinatal education. The idea for the research project arose from observations made while working as a nursing student on a mother-baby unit. I had observed that cesarean fathers who had participated in the operating room were happier than those who had not been present. There was a dearth of literature on this subject. I conducted a qualitative research study to determine the impact of cesarean birth on fathers. The major findings from this research study (Polomeno, 1981a) were that the fathers who had not participated in the operating room for cesarean birth were less satisfied than those who had participated, had more concerns regarding their wives in the postpartum period and were more helpful in the postpartum period especially with breastfeeding. It is through this study that I became more aware of the impact of the birthing experience on fathers, mothers and especially their relationship.

While doing this research study, I was also clinically interested in the evaluation of objectives for childbirth education classes (Polomeno, 1981b), especially the objectives for breastfeeding and for a spontaneous, vaginal birth. This was a clinical study using quantitative methodology. I had distributed questionnaires to both women and men who had to fill them in together. The first objective on breastfeeding had been met, but not the second one. There was a gap on information regarding cesarean birth. I came to understand how the perspectives of both partners are important in the final evaluation of objectives for childbirth education programs. I asked myself the question how the perspectives of the two partners affect each other and their relationship. I became comfortable with both quantitative and qualitative methodology, I had also obtained training in family nursing assessment and intervention while in this master's program. The theme of the couple in the context of perinatal nursing emerged from both studies and will be at the heart of my eventual research program and my 30-year clinical practice in perinatal education.

After completion of these studies in 1981, I worked in a tertiary level perinatal unit as a labor and delivery and antenatal nurse where I also implemented childbirth education classes for francophone parenting couples. I was able to change policies and procedures in relation to cesarean birth such as starting a preoperative teaching program and another one for couples visiting the operating room before birth and reducing the preoperative shave. On the one hand, I was happy as I was humanizing perinatal care through the prenatal classes. On the other hand, I was frustrated as I was working in a very interventionist environment: this was my one and only obstacle at that time. I left the hospital to go work as a community health nurse in family and maternal-child health. It was here that I was able to actualize the greatest changes to the health care system. I then taught at the collegiate level and later on, at the university level, both in the undergraduate and graduate nursing programs. 


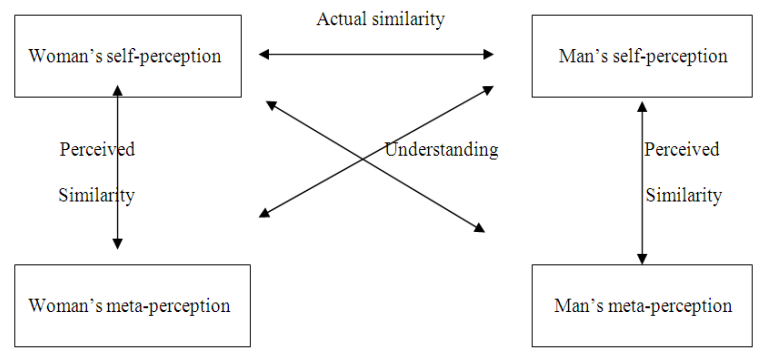

Fig. 1: The interpersonal perceptual approach of the Polomeno family intervention framework

During this time, I combined both my research and clinical interests to do the following: (1) became a certified childbirth educator, (2) created new provincewide hospital policies in which fathers were allowed into the operating room for cesarean birth so that couples could be together, (3) experimented with prenatal programs educating couples about humanizing cesarean birth and VBAC, (4) offered training to perinatal health care professionals about humanized cesarean birth, VBAC and having a more holistic approach to childbirth education, (5) developed self-help groups such as the one for breastfeeding mothers, (6) gave conferences locally, regionally, nationally and internationally on these subjects, (7) got involved with the media such as television, radio and newspapers to disseminate findings to the lay public, (8) worked with the provincial government to change policies in perinatal care and, (9) worked with AWHONN to establish a Québec chapter, organize educational sessions for nurses and establish a national research committee.

I was very fortunate as the health care system was ready for these changes. Also, I had established important partnerships with colleagues in perinatal care in both the hospital and the community health care systems and within the Ministry of Health and Social Services of Quebec. I learned about mentoring, networking, public speaking, the change process and the importance of interprofessional collaboration. This phase was characterized by implementing changes from empowering the couples themselves to the perinatal health care professionals to the health care system. Indeed, the couple was always at the heart of all these implemented changes.

I had reached a point where I felt I needed more training in research and in couples intervention and more knowledge about the conjugal relationship per se. It was time to go back to graduate school!
The emergence of perinatal sexuality: My doctoral research project (Table 3) focused on couples' stress during high-risk pregnancy and antenatal hospitalization (Polomeno, 2000d). The idea for this research came from several sources: (1) having an interest in couples' research, (2) observing how hospitalized pregnant women and their partners were struggling with the situation, (3) noting how many of the high-risk pregnancies terminated in a cesarean birth and (4) observing the long term consequences of this situation on the couple and the family while working as a community health care nurse. Hoshmand and Martin (1995) explain how the choice of variables selected for focus by a researcher reflect patterns of understanding derived from practice as much as theoretical knowledge from academic training. Also, they write that "the personal knowing comes from immersion in the field and the experience of practicing inquiry" (p. 36). This was a quantitative study using multiple regressions adapted for dyadic research. The interpersonal perceptual approach was integrated into the research design of the study: this involved self-perceptions and meta-perceptions which can be combined to form layers of similarities called actual similarity, perceived similarity and understanding (Fig. 1) (Polomeno, 2000d).

One of the major significant findings that emerged from the study was how a couple's dyadic cohesion which is part of their intimacy is affected by the stress associated with the two stressors (high-risk pregnancy and antenatal hospitalization). This finding emerged at the level of understanding, the third layer of similarity. I could compare this to an iceberg: the $10 \%$ above water is the layer of actual similarity, while the submerged $90 \%$ in the water contains perceived similarity and understanding. This was my first major study in the area of couples' relationships, setting the stage for the beginning of a research program in perinatal sexuality!

To gain more experience with the research process, I had several contracts as a research assistant: I learned about grant writing, writing research reports and articles for publication, data analysis and interpretation, translation and psychometric evaluation of research instruments and preparation for oral and poster presentations. I do recommend having a financial plan in place, both to support the program of studies and the research project itself. This will alleviate stress incurred in relation to this.

While I was pursuing doctorate studies, I continued to function in the dual roles of clinician and researcher that I had originally learned in my master's program. From a clinical viewpoint, I had obtained new training in couples' intervention, adding to the training in family intervention acquired in the master's program. 
Intl. J. Rec. Nursing 1 (2): 39-56, 2010

Table 2: Workshops created for a clinical practice in perinatal education

\begin{tabular}{lll}
\hline Year & Title of workshop & Publication of corresponding article \\
\hline 1996 & Postnatal sexuality & Polomeno (1996a) \\
1996 & Social support during pregnancy & Polomeno (1996b) \\
1996 & Creating family intimacy through fetal touch & Polomeno (1998a), Polomeno (1999f) \\
1997 & High-risk pregnancy & Polomeno (1997b) \\
1997 & Intimacy and pregnancy & Polomeno (1997d) \\
1998 & Health promotion for expectant fathers & Polomeno (1998b), Polomeno (1998c) \\
1998 & Labor and birth: Supporting a couple's intimacy & Polomeno (1998d), Polomeno (1998e) \\
1999 & Family health promotion from the couples' perspective & Polomeno (1999e), Polomeno (1999f) \\
1999 & Sex and breastfeeding & Polomeno (1999d) \\
1999 & Perinatal education and grandparents: Creating an interdependent family environment & Polomeno (1999b), Polomeno (1999c) \\
1999 & Sex and babies: Pregnant couples' postnatal sexual concerns & Polomeno (1999a) \\
2000 & Preparenthood and pregrandparenthood & Polomeno (2000c) \\
2000 & Sex and pregnancy & Polomeno (2000b) \\
\hline
\end{tabular}

Table 3: Preliminary findings from the first group of studies

\begin{tabular}{|c|c|c|c|c|}
\hline \multirow[b]{2}{*}{$\begin{array}{l}\text { Study \# and } \\
\text { Fsocus of study }\end{array}$} & \multirow[b]{2}{*}{ Sample } & \multicolumn{2}{|c|}{ Studies Relating to the Polomeno Iintervention Framework } & \multirow[b]{2}{*}{$\begin{array}{l}\text { Impact on the Polomeno } \\
\text { Framework }\end{array}$} \\
\hline & & - & Major results & \\
\hline $\begin{array}{l}\text { \#1 Perinatal } \\
\text { education and } \\
\text { grandparents } \\
\text { (Polomeno, 1999b; } \\
\text { 1999c) }\end{array}$ & $\begin{array}{l}29 \text { grandparents (21 } \\
\text { grandmothers, } 8 \\
\text { grandfathers) }\end{array}$ & $\begin{array}{l}\text { 1. Group interview } \\
\text { 2. Anonymous self } \\
\text {-administered questionnaire } \\
\text { containing fixed and } \\
\text { open questions }\end{array}$ & $\begin{array}{l}\text { Group Interview: } \\
\text { 1. Reasons given for } \\
\text { attendance: they were } \\
\text { curious about the } \\
\text { workshop, 2) their } \\
\text { children has asked them } \\
\text { to come so they grandparents } \\
\text { (GPs) wanted to please them, } \\
\text { 3) needed clarity on the } \\
\text { grandparental role in } \\
\text { today's context, 4) they wanted } \\
\text { to e on the same wavelength } \\
\text { as their children in terms of the } \\
\text { latest information, 5) they } \\
\text { wanted to be a "good grandparent" } \\
\text { 2. The group expresses } \\
\text { overall satisfaction with } \\
\text { the information given, the } \\
\text { program's organization, the } \\
\text { group dynamic approach, the } \\
\text { written and audiovisual } \\
\text { materials and the comfort of the } \\
\text { setting } 3 . \text { More specific results: } \\
\text {-the GPs knew more about } \\
\text { what to expect from the two } \\
\text { generations, how to support the } \\
\text { new family and how to be more } \\
\text { sensitive to what their children } \\
\text { were going through } \\
\text { Anonymous questionnaire: } \\
\text { feeding, the group approach was } \\
\text { well-structured, the setting was } \\
\text { comfortable and the audiovisual } \\
\text { and written materials were effective. } \\
\text { all the participants felt that it } \\
\text { was clear, welcoming and that it } \\
\text { piqued their interest and curiosity } \\
2 . \text { The following items had a high } \\
\text { level of satisfaction (either } 9 \text { on } \\
\text { 10 or } 10 \text { on } 10 \text { on a scale from } \\
\text { "very dissatisfied" to "very satisfied": } \\
\text { how to help the new family, they felt } \\
\text { up }\end{array}$ & $\begin{array}{l}\text {-The transmission of intimacy } \\
\text { was being assessed in } \\
\text { this study, especially } \\
\text { transgenerationally } \\
\text {-Conjugal intimacy was } \\
\text { intertwined with } \\
\text { family intimacy } \\
\text {-Transition to } \\
\text { parenthood: } 2 \text { phases } \\
\text { were involved: preconception } \\
\text { and pregnancy } \\
\text {-Only self-perceptions } \\
\text { were considered } \\
\text { (actual similarity) } \\
\text {-Mediators: Communication } \\
\text { between the generations } \\
\text { was being assessed } \\
\text { as well as the support that } \\
\text { future and actual } \\
\text { grandparents can } \\
\text { provide to the } \\
\text { generation of the } \\
\text { parenting couples. } \\
\text {-Anticipatory guidance } \\
\text { as the educational } \\
\text { modality was also } \\
\text { being assessed } \\
\text {-Content in regard to how } \\
\text { pregnant couples perceive } \\
\text { postnatal sexual changes which } \\
\text { is part of perinatal sexuality was } \\
\text { obtained in this study } \\
\text {-Transition to parenthood: } \\
2 \text { phases were considered, } \\
\text { namely pregnancy } \\
\text { and postpartum } \\
\text {-Only self-perceptions } \\
\text { were considered } \\
\text { (actual similarity) } \\
\text {-Conjugal intimacy } \\
\text { was the focus } \\
\text {-Content for the } \\
\text { workshop emerged } \\
\text { this pilot study. }\end{array}$ \\
\hline
\end{tabular}


Intl. J. Rec. Nursing 1 (2): 39-56, 2010

Table 3: Continuous

\#2Sex and Babies 82 participants (Polomeno, 1999a) (41 couples from 5 prenatal groups)
\#3 Preparenthood -38 participant and pregrand parenthood (Polomeno, 2000c)
1. Questionnaire for sociodemographic and pregnancy data 2. Large sheets of paper: the two subgroups of men and women in each prenatal group listed their concerns separately regarding their postnatal sexual relationship
1. Questionnaire for sociodemographic data 2. Informal group evaluation at the end of the workshop 3. Anonymous self-administered questionnaire
3. All of the participants (all 29 grandparents) had increased their awareness of the grandparental role, its importance on the family, the values that they can transmit and the sharing of the grandchildren amongst the grandparents and between the grandmother and the grandfather 4. Their overall satisfaction with this workshop on a 10-point Likert scale from 1 "not satisfied" to 10 "very satisfied": all the participants rated the workshop as very satisfied.

Sociodemographic and pregnancy questionnaire:

1 . The mean age for

the men was 29.2 years

while for the women

this was 27.5 years.

2. First baby for all couples

3. Average gestation

period: 25.1 weeks

4. 31 couples out of 41 are married

Postnatal sexual concerns (men):

1. pain of first vaginal penetration

2. too much attention on baby and none for him

3. that lovemaking is too planned and not spontaneous enough

4. woman's sexual desire and libido

5 . how baby will change their lives

6. fatigue

7. how to please partner

8.postpartum depression

9. birth complications and impact

on sexual relationship

10. timing of first intercourse

Postnatal sexual concerns (women):

1.pain of first penetration

2. to feel desired by her partner

3. his perception of her and her

body after birth

4. how male partner is traumatized

from the birth

5. lowered sexual desire

6. does the partner see her as his lover

or as the mother of his child?

7. to find time to make love

8. the women do not want the men to change their behavior as lovers

Sociodemographic

data questionnaire:

Preparental groups

1 . The age range for

both the men and the

women in the

preparental groups

was from early

20 s to late $30 \mathrm{~s}$.

2. Two couples in the first preparental group became pregnant within a few months
-Mediators: Communication, social support, maintenance behaviors and equality were explored in this study

\author{
-Conjugal intimacy was \\ assessed in this study \\ as well as family \\ (transgenerational) intimacy \\ -Transition to parenthood: \\ 3 phases were involved, \\ that of the decision \\ to become pregnant, \\ preconception and pregnancy \\ -Only self-perceptions \\ were considered \\ (actual similarity) \\ -Mediators: communication, \\ social support \\ assessed in this study \\ -Anticipatory guidance \\ as the educational \\ modality was also \\ being assessed
}


Intl. J. Rec. Nursing 1 (2): 39-56, 2010

Table 3: Continuous

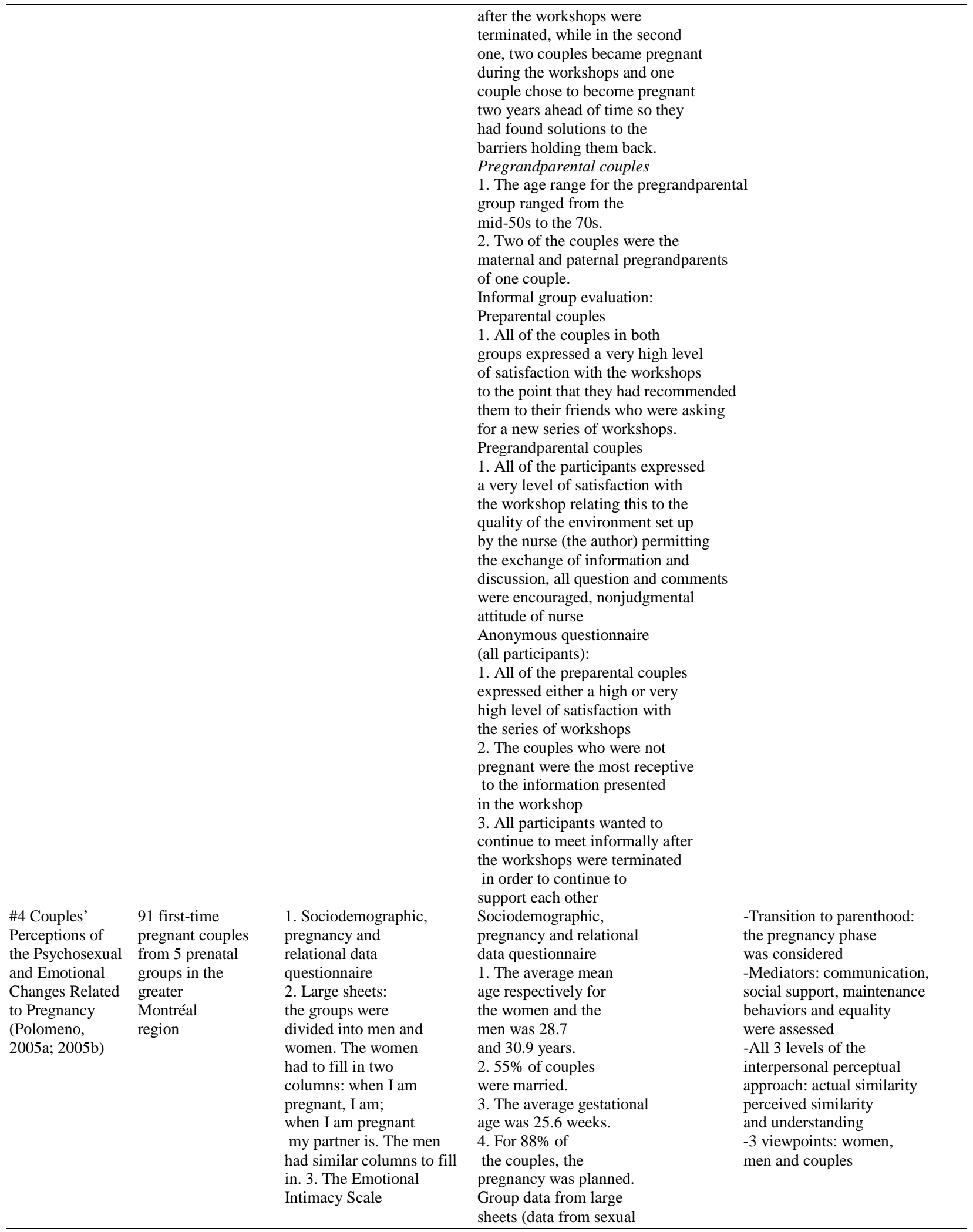


Intl. J. Rec. Nursing 1 (2): 39-56, 2010

Table 3: Continuous

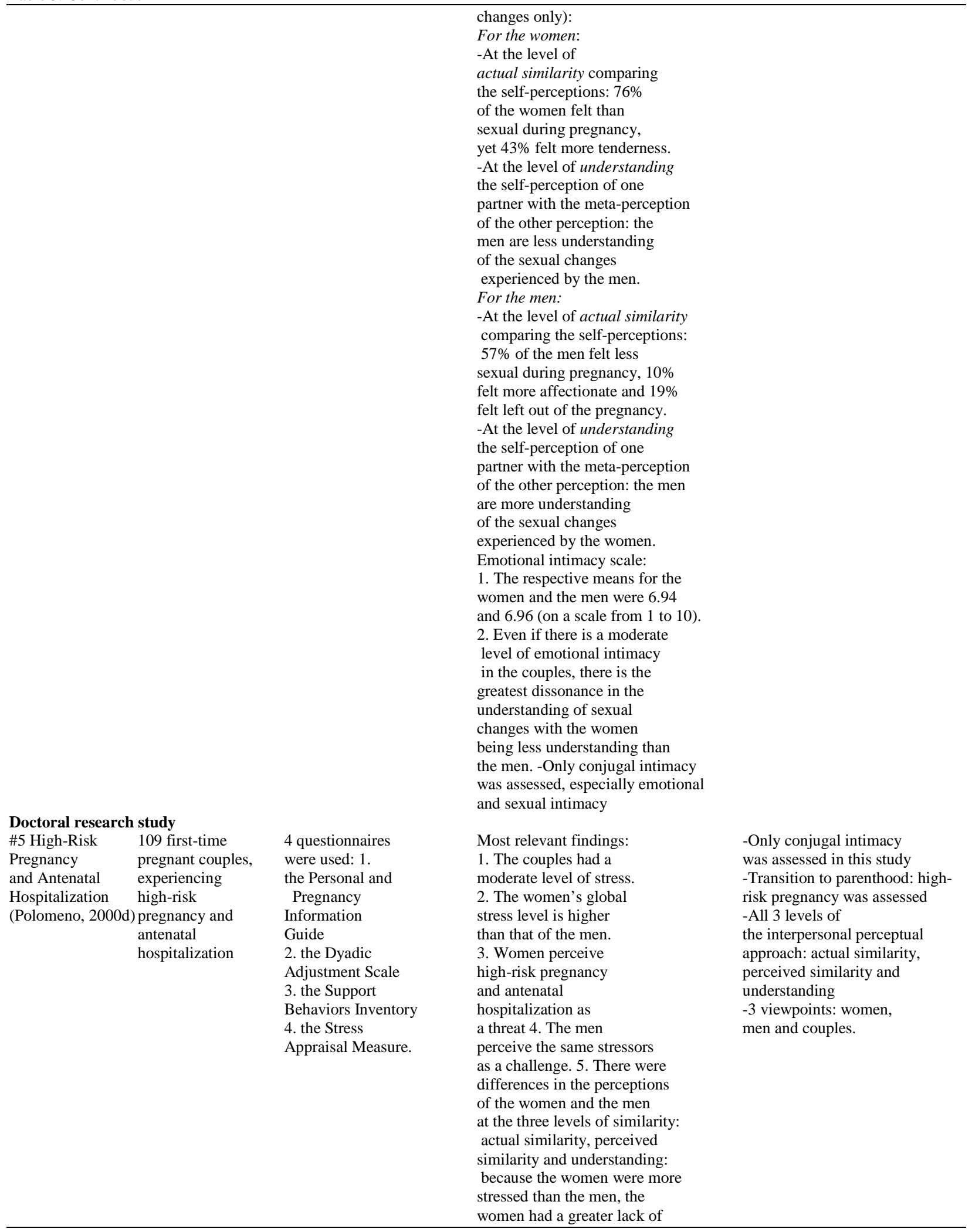


Intl. J. Rec. Nursing 1 (2): 39-56, 2010

Table 3: Continuous

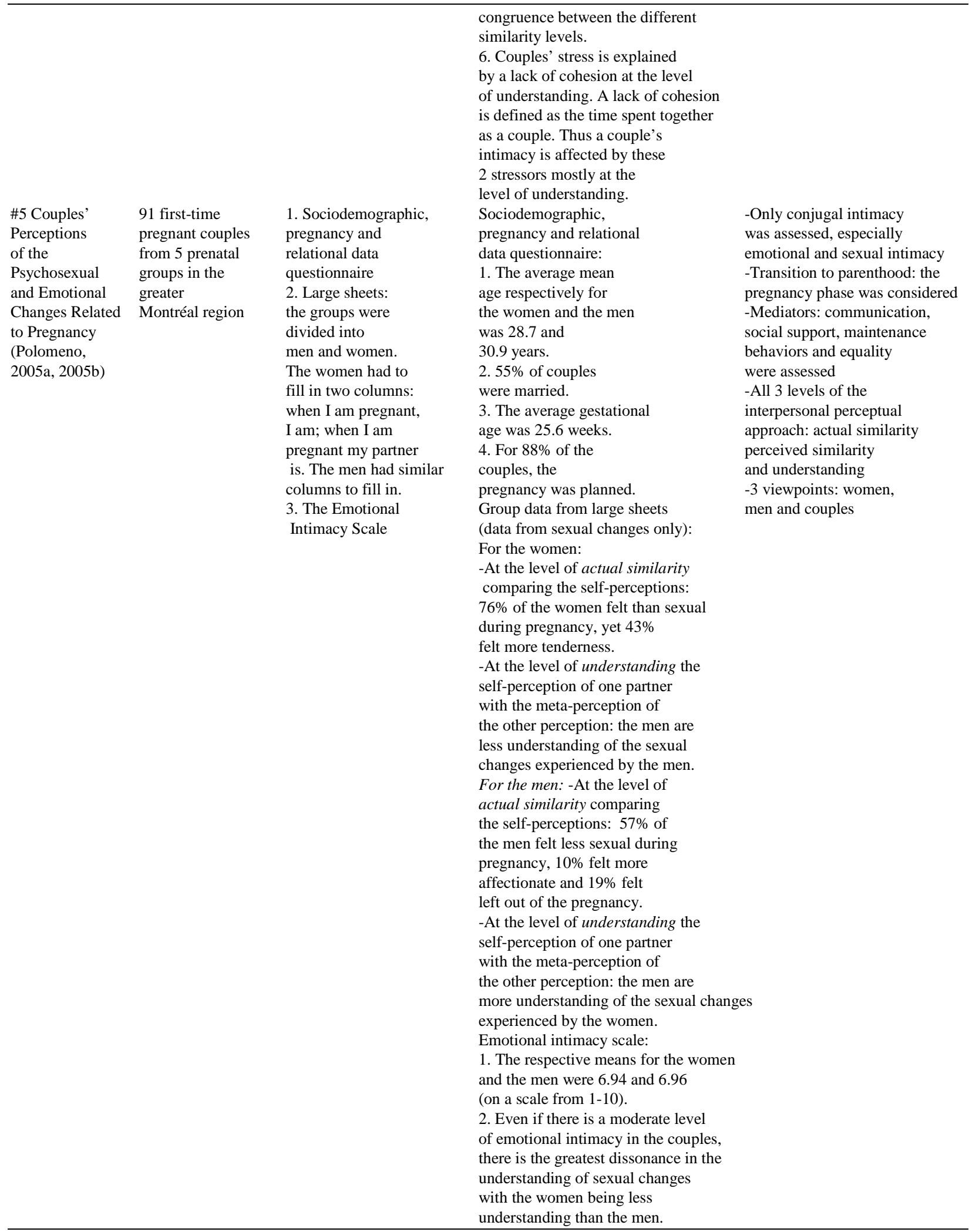


I integrated this new training into my perinatal education practice. This was an interesting and enriching experience for me. Since I was conducting research on high-risk pregnant couples, I had a need to continue to be exposed to the low-risk pregnant ones in my practice. There was a continuous comparison going on between the two groups, research-wise and clinically. This anchored my new knowledge and skills. I was exploding with creativity! For example, I was able to transpose the interpersonal perceptual approach from my research study and integrate it into my clinical practice. The traditional approach that I had been using in my prenatal classes now became couples' focused and 'classes' turned into 'workshops', emphasizing interactivity and exchange of information. The onus was more on what happens to the relationship during the workshops rather than on the content per se. I became a research and clinical expert on the couple's relationship during the transition to parenthood.

I started to write about the experimentation with my practice in perinatal education. I published articles in peer-reviewed international journals that were either clinically focused such as postnatal sexuality, or about the workshops themselves. My first published workshops focused on pregnancy, pregnant fathers, the intrapartum and breastfeeding, while the later ones were expanded to include grandparents and preparenthood. The publication dates of my articles reflect the order of my experimentation. The later workshops that I was developing were focused more at the beginning of the continuum of the transition to parenthood. Why is this? Couples taking my workshops that were occurring during pregnancy or postnatally would encourage me to give the information to couples who wanted to get pregnant or were thinking of becoming parents. Then, the couples taking the latter workshops would ask me to give information to their own parents. Ideas for workshops always emerged from their summative evaluation: couples would provide suggestions on how to improve the workshops.

Eventually, I developed 13 workshops (Table 2) in the domain of perinatal sexuality with such themes as postnatal sexuality, intimacy during pregnancy, intimacy during labor and birth, sex and pregnancy and, sex and breastfeeding (Polomeno, 1996a; 1996b; 1997a; 1997b; 1997c; 1997d; 1998a; 1998b; 1998c; 1998d; 1998e; 1999a; 1999b; 1999c; 1999d; 1999e; 1999f; 2000b; 2000c). Dissemination of this experimentation was important to me so that my perinatal colleagues could also experiment with their own practice in perinatal education. The translation of knowledge became part of the process of combining research with clinical practice.
A new phase: Conceptualization: As I was starting to establish my research program through my doctoral research study and expanding my clinical practice, I entered a new phase involving the conceptualization of my work. This was another way to combine research with clinical practice. Many colleagues were asking me questions about the theoretical framework underlying the workshops that I had developed and the conceptualization behind it. Initially, the framework guiding my practice was based on family health promotion (Bomar, 2004) which I had been exposed to while pursuing doctoral studies. Hanson et al. (2005) presents a definition of family health promotion in an earlier publication: "behaviors of the family that are undertaken to increase the family's well-being or quality of life...activities families engage in to strengthen the family as a unit". Implicit in this definition is the family subsystem, namely, the couple's relationship. Bomar mentions how emotional health is part of family health promotion. For me, this meant the couple's well-being and the intimacy in their relationship. Family health promotion is a central component of comprehensive primary prevention programs such as perinatal education workshops. Such primary prevention programs are "designed to prevent problems before they develop by modifying the external conditions that cause problems or by helping people cope with these conditions... are aimed at healthy targets during a life transition" (Michaels and Goldberg, 1993). Thus, each workshop that I had developed and published was a primary prevention program in family health promotion. There are also secondary and tertiary prevention programs.

I adapted and expanded on the concept of family health promotion by developing my own framework, entitled "The Polomeno Family Intervention Framework for Perinatal Education: Preparing Couples for the Transition to Parenthood (Polomeno, 2000a). This framework (Fig. 2) focuses on the couple's relationship in the transition to parenthood, particularly on intimacy and sexuality. Intimacy is the concept at the heart of the framework since it is the dimension that is the most affected in this transition. Intimacy is seen from both a conjugal and a familial perspective, leading to an interdependent intergenerational family environment. Communication, social support, conjugal maintenance behaviors and equality mediate the intimacy of the parenting couple's relationship. Intimacy, both conjugal and family, is defined in the following way. "Conjugal intimacy is foundational for intimacy within the whole family" (Polomeno, 2000a). "Family intimacy is critical...since the family will [ideally] become the safe haven for each of its members. 


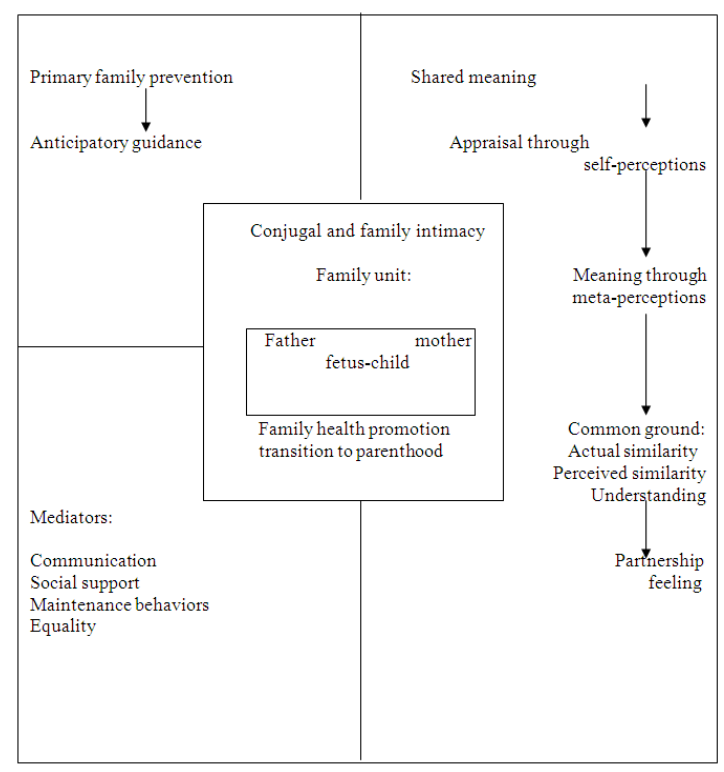

Fig. 2: The polomeno family intervention framework for perinatal education: couple's preparation for the transition to parenthood

The sense of security the family produces will have beneficial consequences, both short-term and longterm, for their unborn's development and the development of other children to follow" (Polomeno, 1998a). Schafer's definition of intimacy was adapted for both conjugal and family intimacy: "True intimacy is a process that grows with time. It is a process of knowing and being known and it requires openness and willingness from each person involved. Intimacy has no techniques... [and] cannot be orchestrated. It starts with the self, knowing the self and being present to the self...intimacy is not static. It is always moving to a new level. It is an energy flow with no barriers...[and] cannot be controlled. Like a feeling, it cannot be held onto or reproduced. We notice intimacy. We do not produce it" (Schaef, 1990).

Intimacy depends on how a couple stays connected and they do so through their perceptions which are the exchange of their viewpoints and how they find meaning in a situation. The application of intimacy within the Polomeno framework relies on the Interpersonal Perceptual Approach (IPA). The IPA (Fig. 1) is used actively within the workshops and also in a research context. This approach uses a combination of self-perceptions and meta-perceptions to form three layers of similarity: actual similarity, perceived similarity and understanding. When a person presents his or her own opinion about a situation, this is called a self-perception. When a person is able to present another person's perception or what he or she thinks the other person is thinking, this is called a metaperception. Combinations of self-perceptions and metaperceptions produce 3 types of similarity. The first type which is also the first layer of perceptions, actual similarity, is the comparison of the self-perceptions of the two partners. In the second layer, perceived similarity, one person's self-perception is compared with his or her own meta-perception: what this means is that the person's own perception is compared to what he or she thinks the other partner is thinking about a situation. In the last layer of intimacy, understanding, one person's meta-perception (what he or she thinks that the other is thinking) is compared with the other partner's self-perception.

Furthermore, I was expanding on the definition of transition to parenthood. I had read two very important articles on transitions (Meleis and Trangenstein, 1994; Schumacher and Meleis, 1994) which were proposing that the concept of transition be added to the metaparadigm of nursing. For me, the transition to parenthood is the time period that a couple will experience beginning with the decision to become pregnant and ending when the child is two years old (Polomeno 2000a). The transition to parenthood contains nine phases: (1) the decision to become pregnant; (2) physically creating the baby; (3) pregnancy; (4) birth; (5) the immediate postpartum, including the first 6 weeks; (6) $11 \frac{1 / 2}{2}$ to 6 months postpartum; (7) 6-12 months; (8) 12-18 months; and (9) 18-24 months. The transition to parenthood can be considered as complete when the child is 2 years old (Polomeno 2000a).

Anticipatory guidance (Polomeno, 2006) is the educational modality (Belsky and Kelly, 1995) underlying the structure of each workshop (Polomeno, 2000a). The goal of anticipatory guidance is to strengthen family systems in the transition to parenthood (Belsky and Kelly, 1995). Since the emphasis is on the coupleship, partnership relationship enrichment as an approach is integrated into anticipatory guidance. In this approach, the couple discusses any changes that they are experiencing through the IPA, the partners support each other and nurture their relationship in order to stay connected throughout the transition to parenthood. Couples stay connected through intimacy which is explored in the context of the phases of the transition to parenthood. The group environment that is set up in each workshop is important: the workshop becomes a type of safe haven where each individual and each couple feel secure to learn, to share thoughts and feelings and to communicate any fears that may arise. The training 
from couples and family interventions become useful in this type of clinical situation. Couples develop an impression that they are not alone, that there are others who are also experiencing the same life situation.

\section{Preliminary Findings from the First Group of} Studies: Once the intervention framework had been developed and published, I started to conduct research using mixed methodology on several workshops with three objectives: (1) to test parts of the Polomeno framework, (2) to understand how intimacy and sexuality change in a couple's relationship in the transition to parenthood and (3) begin to develop perinatal sexuality as a research and clinical domain. This is practice-based programmatic research. Table 3 presents preliminary findings from 4 studies. They have been published in various international journals and disseminated at several national and international conferences. One study was funded externally by a government agency while the other four studies were conducted within my private perinatal education practice. All couples had given informed consent to participate in the studies.

In the first study (Polomeno, 1999b; 1999c), grandparents attended a workshop in which they learned about their roles and how to assist the younger generation-their children. Data were gathered at different levels to test the content, to assess parts of the Polomeno intervention framework and to understand intimacy from a transgenerational viewpoint. Although there was a high level of satisfaction with the content of the workshop, the participants specifically mentioned how they had more knowledge to help their children who were in the process of becoming parents (social support), how to communicate in regard to childbearing and childrearing and how to enact their roles of grandparents. Also, there was appreciation for the discussion of family intimacy and its impact on the family system.

In the second study (Polomeno, 1999a), 41 pregnant couples were asked about their perceptions for their postnatal sexual relationship. The women and the men each listed their concerns which could be divided into 4 themes: physical matters, psychological issues, adaptation issues and anticipatory planning. The women and the men had many similar concerns, yet there were differences between the two groups. The article that I wrote is unusual in that it not only presented the results of this research study, but at the end of it, I proposed content for a new workshop for perinatal educators. The content had emerged from the findings of this study.

The third study (Polomeno, 2000c) presented the findings from a series of workshops on preparenthood and pregrandparenthood. Two groups of non-pregnant couples assisted at a series of workshops on the theme of intimacy and parenting. The focus was on the changes in the conjugal relationship during the transition to parenthood. The parents of the second group were invited for a special workshop on pregrandparenthood. This study permitted me to assess transgenerationalism which is the interdependent intergenerational family environment as described in the Polomeno framework. The IPA was utilized in all of the workshops. The findings reveal that the participants were very satisfied with the content and the approach used in the workshops, 2 couples became pregnant within a few months of the workshops and another 2 couples became pregnant during the workshops. The workshops had helped the couples to sort out their feelings about parenting and felt that there were no more fears or obstacles to becoming pregnant.

In the last study (Polomeno, 2005a; 2005b), 91 pregnant couples expressed their perceptions about the psychosexual and emotional changes during pregnancy. The IPA was used in the data collection methods. Again, the most significant results were at the third level of understanding. For example, the women were less understanding of the sexual changes occurring in the men during pregnancy. I was asking myself if this can partially explain why certain couples separate during pregnancy.

Here are some of the conclusions that I have drawn from the above studies which included 302 pre- and parenting adults and 37 pre- and grand parenting ones. First, men and women have different perceptions regarding intimacy in the transition to parenthood with an impact on their relationship. Second, how grandparents view intimacy is different than that of the parenting couples, yet they are complementary to create family intimacy. Third, the most significant results occurred at the level of understanding. Fourth, the interpersonal perceptual approach is a very powerful one that can be used both in research and clinical practice. Fifth, preparation for intimacy in the context of the transition to parenthood is helpful for couples to preserve their relationship. This preparation can occur even when a committed couple is thinking of having a child. Lastly, perinatal sexuality has great potential as both a research and clinical domain. More work is needed to continue to evaluate the Polomeno Intervention Framework. 
At the end of these 4 studies, I had several questions such as: how does intimacy change in the transition to parenthood? How can perinatal educators better prepare couples for this transition? How can perinatal health care professionals be more aware of the intimacy and sexual changes occurring in couples' relationships in the transition to parenthood? What training do perinatal health care professionals receive in perinatal sexuality?

My present research program in perinatal sexuality: In 2006, I moved from Montréal to Ottawa, Canada's national capital. I accepted a teaching position as an assistant professor with the School of Nursing at the University of Ottawa-Université d'Ottawa. This nursing school offers undergraduate and graduate nursing programs in Canada's two official languages of French and English. I teach on the francophone side. I accepted the position at this particular school of nursing as I wanted to conduct research and teach, but also to continue to have a clinical practice in perinatal education. In this position, a professor's time is divided as follows: $40 \%$ for research, $40 \%$ for teaching and $20 \%$ for service which includes clinical practice. I will first describe my practice-based and evidencesupported research program followed by my evolving practice in perinatal education.

Establishing my research program was not easy. I had been very entrenched in Québec's health care system and did not know the Ontario one (Ottawa is in the Province of Ontario). I had to start from scratch. I had to learn about the health care system in Ontario and the one in the City of Ottawa, establish a partnership with colleagues in the perinatal health care network and set up a research network for my research program. The University of Ottawa has a mentorship program for new professors. The mentorship program was useful for me as I needed help to get organized research-wise in a new environment and support for grant writing. I did not get funding for the first two research grants that I had written, however, I was successful with the next one. Hoshmand and Martin (1995) write how the development of a researcher parallels the progression of inquiry.

My present research program is entitled, "AmisAmants-Parents", which translates into English as "Friends-Lovers-Parents". At this point in time, I was more interested in conducting research with perinatal health care professionals. Upon my arrival, I was meeting with different colleagues in the health care system to introduce myself and to establish contact with them. After several months, it became quite clear that perinatal health care professionals are uncomfortable with discussing sexuality, have little or no training for it and have no training in sex research. Reactions to my presentations were always positive and my colleagues expressed great enthusiasm for the domain of perinatal sexuality. So instead of focusing my first research study on the clientele, I preferred to focus on the perinatal health care professionals, particularly perinatal nurses in public health. This first study (Table 4) was supported with internal funding from the Faculty of Health Sciences of the University of Ottawa.

My next challenge was to become a member of a research institute. Hôpital Montfort is a francophone hospital in Ottawa and the only one in the Province of Ontario offering services to the francophone population. I became a member of its research institute and established a partnership with its family birthing centre. In speaking with the clinical nurse specialist of this unit, I was wondering how 'family' was the family birthing centre in regard to fathers. Moreover, I was also interested in fathers' intimacy and sexuality needs in the transition to parenthood. Successful external funding was obtained for this second study from the Consortium national de formation en santé.

I continued my interest with perinatal health care professionals and perinatal sexuality. The next study was externally funded by the Academic Health Council Champlain Region. The purpose of this third study is to evaluate an interprofessional training workshop on perinatal sexuality for perinatal health care professionals. This is a pilot study. A fourth study was internally funded to replicate this training workshop in another Canadian city but with two groups of francophone and anglophone perinatal health care professionals.

As I was developing my interest for perinatal sexuality and slowly interacting with the family birthing centre at Hôpital Montfort, I was becoming more aware of francophone parenting couples living in Ottawa, of their needs and how they were not being met. This, the first focus of my research program is on perinatal sexuality and the second one is on francophone parenting couples in a minority situation in Ottawa and in Eastern Ontario. I had attended a oneweek summer institute training workshop given by the Canadian Institutes of Health Research on how to conduct research with the Official Language Minority Communities (OLMC) or CLOSM in French, translated as Communautés de langue officielle en situation minoritaire. A colleague and I both have obtained external funding as principal investigators from the Consortium national de formation en santé for an interdisciplinary research study, the fifth one, to trace the profile of francophone parenting couples who give birth at the family birthing centre of Hôpital Montfort. 
Intl. J. Rec. Nursing 1 (2): 39-56, 2010

Table 4: My present research program

Title of study about Perinatal Sexuality of Public Health Nurses Working in Perinatal Health in Ottawa and Eastern Ontario
Une étude comparative entre les perceptions des pères et celles des infirmières concernant les besoins des pères francophones en situation minoritaire au Centre familial de naissance de l'Hôpital Montfort (A comparative study between fathers' and nurses' perceptions regarding the needs of francophones fathers in a minority situation at the Family Birthing

Centre of Montfort Hospital)

A pilot study evaluating an interprofessional training workshop in perinatal sexuality

A Pilot Study: A Bilingual Interprofessional Training Workshop in Perinatal Sexuality for Health Care Professionals in Regina, Saskatchewan

Portrait de familles francophones en situation minoritaire qui donnent naissance à l'hôpital Montfort: Enquête sur les déterminants de la santé (Profile of francophone families living in a minority situation who give birth at Hôpital Montfort: Survey of health determinants)

Purpose of study Source of funding \\ To assess the attitudes and knowledge \\ of public health nurses working in \\ perinatal health in Ottawa and in Eastern \\ Ontario regarding perinatal sexuality \\ To determine the influence of professional \\ and sociodemographic variables on these public \\ health nurses' attitudes and knowledge \\ about perinatal sexuality \\ To compare data from different data collection \\ methods regarding perinatal sexuality \\ Faculty of Health Sciences, University of \\ Ottawa
}

To compare the perceptions between the francophone fathers in a minority situation and nurses during the perinatal period regarding fathers' needs

To determine of the needs of fathers are being met by the nurses working at the Family Birthing Centre (the needs include those for intimacy and sexuality).

To evaluate an interprofessional training workshop for perinatal health care professionals in perinatal sexuality. To assess the knowledge, attitudes and comfort levels of the workshop participants before and after the training program.

To evaluate an interprofessional training workshop for perinatal health care professionals in perinatal sexuality. To assess the knowledge, attitudes and comfort levels of the workshop participants before and after the training program.

To determine the sociodemographic profile of francophone individuals couples/families who give birth at/

Montfort Hospital

To identify the biopsychosocial and environmental health determinants that affect francophone individual/ couples/families in a minority situation going through the transition to parenthood

To identify health services utilized by individual/couples/families et access conditions for these services
I'm responsible for the intimacy and sexuality components of this study. The team research is composed of nurses, psychologists and an anthropologist.

One of my research challenges has been to develop an instrument to measure perinatal sexuality among perinatal health care professionals such as obstetriciansgynecologists, family physicians doing obstetrics, nurses, midwives, doulas and perinatal educators. A literature review provided items for the first version of the Polomeno Perinatal Sexuality Scale (PPSS). Two versions were created, one in English and the other in French. Items for the PPSS were obtained from my writings (Polomeno, 1996a; 1997d; 1998d; 1998e; 1999d; 1999a; 2000b). Content validity was carried out with a bilingual panel of expert perinatal nurses. Two more versions followed in response to results from content validity. The third version of the PPSS is currently being tested in 3 of 5 projects: see Projects \#1, 3 and 4 in Table 4.

Clinically, I continued to evolve my practice in perinatal education. I had transferred my practice from 
Québec to Ontario by establishing the Polomeno Perinatal Centre (www.violapolomeno.com), developing a marketing approach by being called The Love Nurse or L'Infirmière de l'amour and experimenting with new workshops. The first workshop is entitled 'Thinking about Parenthood' and its content is presented in my article on advanced practice in perinatal education (Polomeno, 2009b). The second one is called 'Preconception'. Upon my arrival in Ottawa, I continued my clinical training by obtaining preparation in sexual intervention from Guelph University. I was now trained in couples, family and sexual intervention. As I was experimenting with new workshops and establishing my research program, I began to write a series of reflection papers on perinatal sexuality as a domain and in relationship to perinatal education (Casse and Polomeno, 2009; 2010; Polomeno, 2006; 2007a; 2007b; 2007c; 2009). These articles helped me to integrate my research with my clinical practice and to advance the conceptualization of intimacy in the transition to parenthood. Presently, I have submitted 2 articles on vulnerability in a couple' relationship during the transition to parenthood to an international journal. There is a dearth of literature in regard to this concept. This is surprising as vulnerability is such a great part of love and intimacy.

Knowledge translation is emerging more and more for me. Since my arrival in Ottawa, I have been involved with the public by appearing on French and English television, talking on radio in both languages and being interviewed by journalists for local francophone and anglophone newspapers. Integrative knowledge is more prominent than end-of-grant knowledge translation. Giving informal and more scientific presentations and conferences within the university and outside of it are increasing, with a consequence that I am now receiving invitations to give national and international conferences. I am considered an expert practitioner in perinatal education and perinatal sexuality, so I am on the editorial board of a peer-reviewed journal, am part of a panel of experts for a parenting magazine and its corresponding website and am being invited to give my professional opinion on different subjects for international parenting newsletters and for provincial governments on their policies for perinatal care. My recognized expertise has also led me to be part of the Social and Sexual Issues Committee of the Society of Obstetricians and Gynecologists of Canada and to write chapters in maternal-child health nursing textbooks in both French and English. A final consequence has been the creation of a reflective group on sexuality and health care for nurses working at The Ottawa Hospital: seventeen nurses from different domains have come together to discuss such topics as how to give sexuality information to patients, how to sensitize other health care professionals and how to be more personally comfortable with sexuality. The group is presently compiling a list of resources and preparing a hospital-wide survey on nurses' learning needs relating to sexuality.

And what about the future? The future will involve theory, research, clinical practice, education and knowledge translation. For theory, I will continue to function in what Randolph-Seng (2006) calls theory building top-down and bottom-up. He explains that when using a top-down process, the advantage is that a guide can be provided at a functional level while the disadvantage is that the researcher can ignore or misinterpret unexpected findings. For a bottom-up process, the advantage is that the researchers are free to explore many possibilities in their research, thus allowing for a fast accumulation of evidence, although they may be unable to always clearly explain why they found what they did. A bottom-up inductive process will more naturally allow for a functional perspective to emerge.

Research-wise, my present research program will continue for the next three years. More grant money will be required for other projects which are in the planning phase. Two projects in particular are very interesting: the first one will involve a national survey of perinatal health care professionals regarding perinatal sexuality and the other will focus on alternative sex during the perinatal period. Clinical outcomes will be more integrated into the projects. Two colleagues and I are in the throes of setting up a new interdisciplinary family research unit at Hôpital Montfort; within this research unit, I will have a research group on perinatal sexuality.

Clinically, I will be creating a new workshop called The Baby Project which will be given to newly engaged couples or recently married couples who have taken marriage preparation courses. This separate three-hour workshop will explore the question of having children, how to prepare for them and how to keep connected emotionally while having them. From an education viewpoint, the process has been initiated to develop a graduate certificate for health care professionals on sexuality and health care at the University of Ottawa. This will be the first certificate of this type being offered in Canada, moreover in both French and English. My goal is make health care professionals, those in training and those in practice, savvy about couples, their relationship and their sexuality. Lastly, from the viewpoint of knowledge translation, the nursing sexuality reflective will be expanded to include other health care professionals and to go regional. A 
regional round table or a table de concentration will focus on addressing the issues relating to sexuality within Ottawa's health care system.

What have I learned about establishing a research program? Learning how to establish a research program was not easy and not always evident. It was a long process, but the motivation to discover the world of research and to find the answers to the questions that I was asking myself were a great impetus.

So what are the lessons that I have learned along the way?

Start somewhere: Getting into a nursing program is a start. Most nursing programs have a course in nursing research. If at all possible, get involved with a research study while doing your undergraduate degree, or after the completion of these studies. You can help with the literature review, recruitment and data collection and the application of findings to clinical practice. If you continue your studies at the graduate level, you continue to take other research courses and do a master's or doctoral thesis which includes a research study. Getting hired as a research assistant will deepen your knowledge of the research process.

Be clear about definitions: This may seem obvious but many nurses are not always cognizant of the definitions such as 'research' and 'research program'.

Think research all the time: Research is a great way to brings nurses together who are concerned about problems that their clientele is experiencing. They can organize reflection groups that explore these problems and decide which ones can be solved through research. Organizing a journal club is another excellent strategy as the nurses read the latest publications and analyze them. This can be part of a literature review to situate the problem that they have identified.

Become an expert in your clinical domain: Gain clinical experience in your clinical domain. Read peerreviewed journals in association with your clinical domain to keep up to date with the latest research occurring in your domain. Be attentive to the research questions that are being explored, of the findings resulting from the studies and their application to practice. Attending workshops and conferences where research studies are being presented is another way for nurses to be aware of research. Discussing clinical observations with one's nurse educator, nurse clinician in advanced practice, or manager may lead to identifying a research question. Becoming and being a reflective practitioner helps a nurse as she or she contemplates over research questions and applying findings to clinical practice.

Postdoctoral fellowship: For certain nurses, taking the time to do a postdoctoral fellowship will help them to establish their beginning of their research program. When doing doctoral studies, a nurse is supervised by a team of doctorally prepared nursing professors. However, when the nurse is doing a "post-doc", she or he is part of a research team, learns how a research team functions, helps to contribute to it and is mentored in the writing of the first grant for external funding.

Partnerships and networking: A research program can be conducted by an individual nurse researcher, yet he or she is in a better position to establish partnerships with colleagues (Koch et al., 2005) in the health care system and other health related agencies for entry into the setting and access to the population for data collection. External funding is more obtainable if the nurse is part of a research team as it is becoming more difficult and more competitive to obtain it. Also, a nurse researcher will be more successful for external funding if she or he is part of an interdisciplinary research team (Koch et al., 2005). Networking is not only local and regional, but also national and international (Borbasi et al., 2005).

Complexity of research program: There are four levels of research from the descriptive, exploratory level to the randomized clinical trial one. A research program may be more basic if no research has ever been done in a particular clinical domain, or it can be more complex, involving multiple centres with an international focus. Research budgets can be from be from a few thousand dollars to millions of dollars.

Choosing one's research partners: One small note of caution here. Choose your research partners wisely and carefully (Borbasi et al., 2005). Being able to work with people who are professional and responsible facilitates the whole research process. Problems increase when there is clash of personalities or when people are not on the wavelength or who hold different values (Tomlinson et al., 1986). Learning to be a team player is an important aspect to accomplish as well as working collaboratively with colleagues in other disciplines. Having good communication skills are always appreciated.

Reading about calls for research: A research program can be born when agencies such as the Canadian Institutes of Health Research or the National Institutes 
of Health publicize grant monies that are available for topics or domains that need to be researched. A nurse researcher must constantly scan and read these announcements as external funding (Koch et al., 2005) is being limited in its availability.

A nurse researcher's connection with clinical practice: If a nurse researcher can maintain some connection with clinical practice (Koch et al., 2005), her or his research will be more grounded. Also, she or he will be able to close the gaps between research and practice or between theory and practice.

Get more training if the need arises: There are always changes and advances in the clinical field of a nurse researcher which will impact the research program. The nurse researcher may be called upon to seek more research training through summer institutes, one-day workshops, webinars and conferences.

Take time for conceptualization: Taking time for conceptualization is important before the start of nay research program, but it should continue during its implementation and afterwards. A nurse researcher can take time to question what advances are being made and how they contribute to theory, or to any concepts that are at the heart of the research program. Getting back to fundamentals is a reality check for the researcher.

Knowledge translation: Knowledge translation has become an integral part of a researcher's research program. There is the end-of-grant knowledge translation such as conferences, poster sessions and writing for publication, but integrative knowledge translation is gaining momentum. More and more researchers are realizing the importance of working directly with the potential population to establish the research questions and methods and to keep them informed as to partial results and discussing the results with them.

Get savvy about the media: The media can be helpful and useful in communicating results about research studies. The various sources are television, radio, newspapers, magazines, internet and social networking. Getting some training in television and radio can be beneficial.

Writing about one's research program: There is a dearth of articles which describe or explain about a nurse's research program. More articles are needed about the lived experience of nurses who put together their research program, the challenges they encountered and the obstacles that they had to surmount. Also, this includes the idea of strengthening the track record of the research team through publications and successful grants (Borbasi et al., 2005).

Supervising graduate students: Involving master's and doctorate students in one's research program makes the whole process more exciting and palpable. They question, they probe, they wonder, they provoke. Wonderful discoveries have been made in interacting with graduate students. Contributing to the development of a future and budding researcher who will one day have her or his own research program is thrilling. Graduate students can eventually become future colleagues with whom more research can be conducted with.

Reflexivity: This last lesson is the most important. Taking time to reflect (Hoshmand and Martin, 1995) on the process and the outcome(s) should be intertwined through the establishment and implementation of a research program. This involves taking time to reflect about the experience itself and the mechanics of managing the research program.

\section{CONCLUSION}

Perinatal sexuality is emerging as a new domain for perinatal health care professionals both researchwise and clinically. Integrating an interdisciplinary approach into a research program is the way of the future. Hooking up with other systems such as the marriage preparation one and the judicial one will provide couples who are thinking of becoming parents complete support from the time of discussing the topic of having children till the children are into the school system. If a couple cannot be together anymore, then co-parenting can be established so that the children continue to receive love from both of their parents. Such a research program has an impact on the family and its members, but also on the health care system and on society itself.

\section{REFERENCES}

Austin, J.K., 2001. Developing a research program. J. Am. Psychiatric Nurses Assoc., 7: 173-176. DOI: 10.1067/mpn.2001.119302

Belsky, J. and J. Kelly, 1995. The Transition to Parenthood: How a First Child Changes a Marriage: Why Some Couples Grow Closer and Others Apart: Based on a Landmark Study. 1st Edn., Bantam Doubleday Dell Publishing Group, Dell, ISBN-10: 0440506980, pp: 288. 
Bomar, P.J., 2004. Promoting Health in Families: Applying Family Research and Theory to Nursing Practice. 3rd Edn., Elsevier Health Sciences, Philadelphia, ISBN-10: 0721601154, pp: 664.

Borbasi, S., C. Emden and D. Jackson, 2005. Nursing research programs gather strength in Australia. Collegian: J. Royal College Nurs. Australia, 12: 710. DOI: 10.1016/S1322-7696(08)60486-2

Casse, I. and V. Polomeno, 2009. Laccompagnement des peres par les infirmieres lors de la naissance dun premier enfant. Soins Pédiatrie-Puériculture, 30: $37-42$.

Casse, I. and V. Polomeno, 2010. ReflexionLadaptation des peres a leur premier nouveau-ne. Soins-Puericulture et Pediatrie, 31: 38-41.

Hanson, S.M.H., V. Gedaly-Duff and J.R. Kaakinen, 2005. Family Health Care Nursing: Theory, Practice and Research. 3rd Edn., F.A. Davis, Philadelphia, ISBN-10: 0803612028, pp: 571.

Hoshmand, L.T. and J. Martin, 1995. Research as Praxis: Lessons from Programmatic Research in Therapeutic Psychology. 1st Edn., Teachers College Press, New York, ISBN: 0807734276, pp: 264.

Koch, T., G. Rolfe and D. Kralik, 2005. Core elements of programmatic research in nursing: A case study. Collegian: J. Royal College Nurs. Australia, 12: 712. DOI: 10.1016/S1322-7696(08)60476-X

Meleis, A.I. and P.A. Trangenstein, 1994. Facilitating transitions: Redefinition of the nursing mission. Nurs. Outlook 42: 255-259. DOI: 10.1016/00296554(94)90045-0 PMID: 7885855

Michaels, G.Y. and W.A. Goldberg, 1993. The Transition to Parenthood: Current Theory and Research. 1st Edn., Cambridge University Press, Cambridge, ISBN-10: 0521455499.

Moore, S.S. and W.W. Singleton, 2009. Sweet steps to an active nursing research program. Nursing, 39: 47-49.

Polomeno, V., 1996a. Sexual intercourse after the birth of a baby. Int. J. Childbirth Educ., 11: 12-15.

Polomeno, V., 1996b. Social support during pregnancy. Int. J. Childbirth Educ., 11: 14-21.

Polomeno, V., 1997a. Creating family intimacy through fetal touch, Part I. Int. J. Childbirth Educ., 12: 10-15.

Polomeno, V., 1997b. High-risk pregnancy: Teaching activities and strategies. Int. J. Childbirth Educ., 12: $14-17$.

Polomeno, V., 1997c. Do you want to know? A brief historical overview of high-risk pregnancy. Int. J. Childbirth Educ., 12: 4-7.

Polomeno, V., 1997d. Intimacy and pregnancy: perinatal teaching strategies and activities. Int. J. Childbirth Educ., 12: 32-37.
Polomeno, V., 1981a. The Impact of Cesarean Birth on Fathers, Montreal: Unpublished master's research project, School of Nursing, University McGill.

Polomeno, V., 1981b. Evaluation of prenatal classes: Analysis of the content of prenatal classes and its application in actual childbirth experiences. Unpublished master's clinical project, School of Nursing, University McGill.

Polomeno, V., 1998a. Creating family intimacy through fetal touch, part II: Practical considerations. Int. J. Childbirth Educ., 13: 20-30.

Polomeno, V., 1998b. Health promotion for expectant fathers. Part II. Practical Considerations. J. Perinatal Educ., 7: 27-36.

Polomeno, V., 1998c. Health promotion for expectant fathers. Part I. Documenting the need. J. Perinat. Educ., 7: 1-8.

Polomeno, V., 1998d. Labor and birth: Supporting a Couple's intimacy, Part 1. Int. J. Childbirth Educ., 13: $18-24$.

Polomeno, V., 1998e. Labor and birth: supporting a couple's intimacy. Part II, Int. J. Childbirth Edu., 13: $16-20$.

Polomeno, V., 1999a. Sex and babies: Pregnant couples' postnatal sexual concerns. J. Perinat. Educ., 8: 9-18.

Polomeno, V., 1999b. Perinatal education and grandparents: Creating an interdependent family environment, Part II: The pilot study. J. Perinat. Educ., 8: 1-11.

Polomeno, V., 1999c. Perinatal education and grandparenting: Creating an interdependent family environment. Part I: Documenting the need. J. Perinat. Educ., 8: 28-38.

Polomeno, V., 1999d. Sex and breastfeeding: An educational perspective. J. Perinat. Educ., 8: 30-42.

Polomeno, V., 1999e. Focal point on childbirth education: Family health promotion from the couple's perspective, part 2: Practical Considerations. Int. J. Childbirth Educ., 14: 31-34.

Polomeno, V., 1999f. Focal point on childbirth education: Family health promotion from the couple's perspective, part 1: Documenting the need. Int. J. Childbirth Educ., 14: 8-12.

Polomeno, V., 2000a. The Polomeno family intervention framework for perinatal education: Preparing couples for the transition to parenthood. J. Perinat. Educ., 9: 31-48.

Polomeno, V., 2000b. Sex and pregnancy: A perinatal educator's guide. J. Perinat. Educ., 9: 15-27.

Polomeno, V., 2000c. Evaluation of a pilot project: Preparenthood and pregrandparenthood education. J. Perinat. Educ., 9: 27-38. 
Polomeno, V., 2000d. First-Time Parenting Couples' Stress Associated with At-Risk Pregnancy and Antenatal Hospitalization. 1st Edn., Universite de Montreal, Montreal, pp: 490.

Polomeno, V., 2005a. Couples' perceptions of the psychosexual and emotional changes relating to pregnancy. Proceedings of the 17th World Congress of Sexology, Jul. 10-15, Allen Press, Inc. Montreal, Canada.

Polomeno, V., 2005b. Les perceptions des couples face aux changements psychosexuels et emotionnels pendant la grossesse. Actes de colloque, Awhonn Canada, Montreal.

Polomeno, V., 2006. Why is love so important in childbirth education? Int. J. Childbirth Educ., 21: 35-44.

Polomeno, V., 2007a. Marriage in the transition to parenthood: How can perinatal education help? Or can it? Int. J. Childbirth Educ.

Polomeno, V., 2007b. Marriage, parenthood and divorce: Understanding the past as we move into the future. Int. J. Childbirth Educ., 22: 13-20.
Polomeno, V., 2007c. Relationship or content? Which is more important in perinatal education? Int. J. Childbirth Educ., 22: 4-11.

Polomeno, V., 2009. La sexoperinatalite: Ou en sommes-nous? Linfirmiere Clinicienne, 6: 20-24.

Randolph-Seng, B., 2006. Doing programmatic research: Two case studies from social psychology. New School Psychol. Bull., 4: 73-90.

Schaef, A.W., 1990. Escape from Intimacy: The Pseudo-Relationship Addictions: Untangling the "Love" Addictions, Sex, Romance and Relationships. 1st Edn., HarperOneFrancisco, Francisco, ISBN: 0062548735, pp: 176.

Schumacher, K.L. and A.I. Meleis, 1994. Transitions: A central concept in nursing. J. Nurs. Scholarship, 26: 119-127. DOI: $\quad$ 10.1111/j.15475069.1994.tb00929.x

Tomlinson, P.S., J.A. Semradek, M.T. Duncan and S.T. Boyd, 1986. Programmatic research: A collaborative model. J. Professional Nurs., 2: 309317. DOI: $10.1016 / \mathrm{S} 8755-7223(86) 80031-\mathrm{X}$ 